\title{
Sensitivity Analysis of the Wave Energy Converters Operating in the French Coastal Waters
}

\author{
F Onea, E Rusu * \\ Department of Mechanical Engineering, 'Dunarea de Jos ' University of Galati, \\ Domneasca Street, 47, Galati 800008, Romania.
}

\begin{abstract}
The aim of the present work is to assess the performances reported by some state-of-the-art wave energy converters which may operate in the vicinity of the French coastal waters. 10 years of wave data (2008-2017) coming from the ERA - Interim project, have been considered and several reference sites have been defined along the French coastlines of the North Atlantic Ocean and of the Mediterranean Sea, respectively. From the assessment of the wave conditions, it was noticed that more important resources are encountered on the north-western parts of the western coasts, while from the eastern coasts the region located between Toulon and Sardinia seems to present interest. As expected, the performances of the wave generators are directly related to the wave energy, although the sites from the eastern coasts are defined by deeper water areas.
\end{abstract}

Keywords: France, coastal environment, wave power, wave energy converters, sensitivity analysis

\section{Introduction}

It is well known that one of the first patents involving a wave energy converter (WEC) was registered in France in 1799 by Girard and son, and although at this moment there are thousands of WEC concepts on the market, we can definitely say that this industry is still in an infancy stage [1]. From the reasons which are behind this situation, we can mention the large number of opportunities in which the kinetic and potential energy of the waves can be extracted, being possible to develop technologies related to heaving float, oscillating water columns or surge devices [2]. Other challenges are related to the survivability of the wave generators in the harsh marine environments, optimal control strategies to increase the WEC efficiency, and also to identify suitable sites for a renewable project [3].

Almost $71 \%$ of the Earth's surface is covered by water, but especially the regions located between $30^{\circ}$ and $60^{\circ}$ latitude in both hemispheres are defined by more attractive wave energy resources for a wave project [4]. France is located in one of this region, being defined by coastlines facing the North Atlantic Ocean and the Mediterranean Sea, respectively. The metropolitan France is characterized by a population of $\approx 63$ millions, a land area of $549970 \mathrm{~km}^{2}$ while the marine sectors cover a total length of $3427 \mathrm{~km}$. Reported to the year 2015, it was estimated that the electricity production was divided between nuclear fuels $(48.8 \%$ ), fossil fuels $(16.1 \%)$ and hydroelectric plants $(14 \%)$, while a percentage of $16.9 \%$ was obtained from other renewable sources [5]. There are ambitious plans to increase the share of renewable by at least $40 \%$ (until 2050) and one solution in this direction will be to consider additional technologies and also the possibility to use an extra source of energy, such as the wave power [6]. From the previous studies, it was noticed that the wave conditions from the French environment seem to be defined by strong intra-annual and inter-annual variations which may report variations of $200 \%[7,8]$.

* Manuscript received May 2, 2018; revised January 3, 2019.

Corresponding author. Tel.: +40-743-932-978; E-mail address: florin.onea@ugal.ro.

doi: 10.12720 sgce.8.2.239-244 
In this context, the following research questions will guide the present work:

a) Highlight the differences noticed between the wave energy conditions from the French coastal sectors located on the North Atlantic Ocean and at the Mediterranean Sea;

b) Assess the performances of several state-of-the-art wave energy converters;

c) Evaluate the sensitivity of the WEC performances, as the water depth and distance to the shoreline increase.

\section{Methods and Materials}

Fig. 1 illustrates the target area where the 15 reference sites (denoted from P1 to P15) were defined along five reference lines. There are two groups of sites, the first is located in the Atlantic Ocean (P1-P9) while the second covers the Mediterranean Sea (P10-P15). Since at this moment there are no operational wave farms it is difficult to establish the specification of such a project, but by looking at the offshore wind industry we can notice that it is possible to implement projects at a maximum distance of $80 \mathrm{~km}$ from the coastline, although a 40-50 km will represent an average value [9]. In order to identify the performance variations of the WECs, three major distances to the shore will be considered: a) $20 \mathrm{~km}$ - P1, P4, P7, P10 and P13; b) $50 \mathrm{~km}-\mathrm{P} 2, \mathrm{P} 5, \mathrm{P} 8, \mathrm{P} 11$ and P14; c) $80 \mathrm{~km}-\mathrm{P} 3, \mathrm{P} 6, \mathrm{P} 9, \mathrm{P} 12$ and P15.

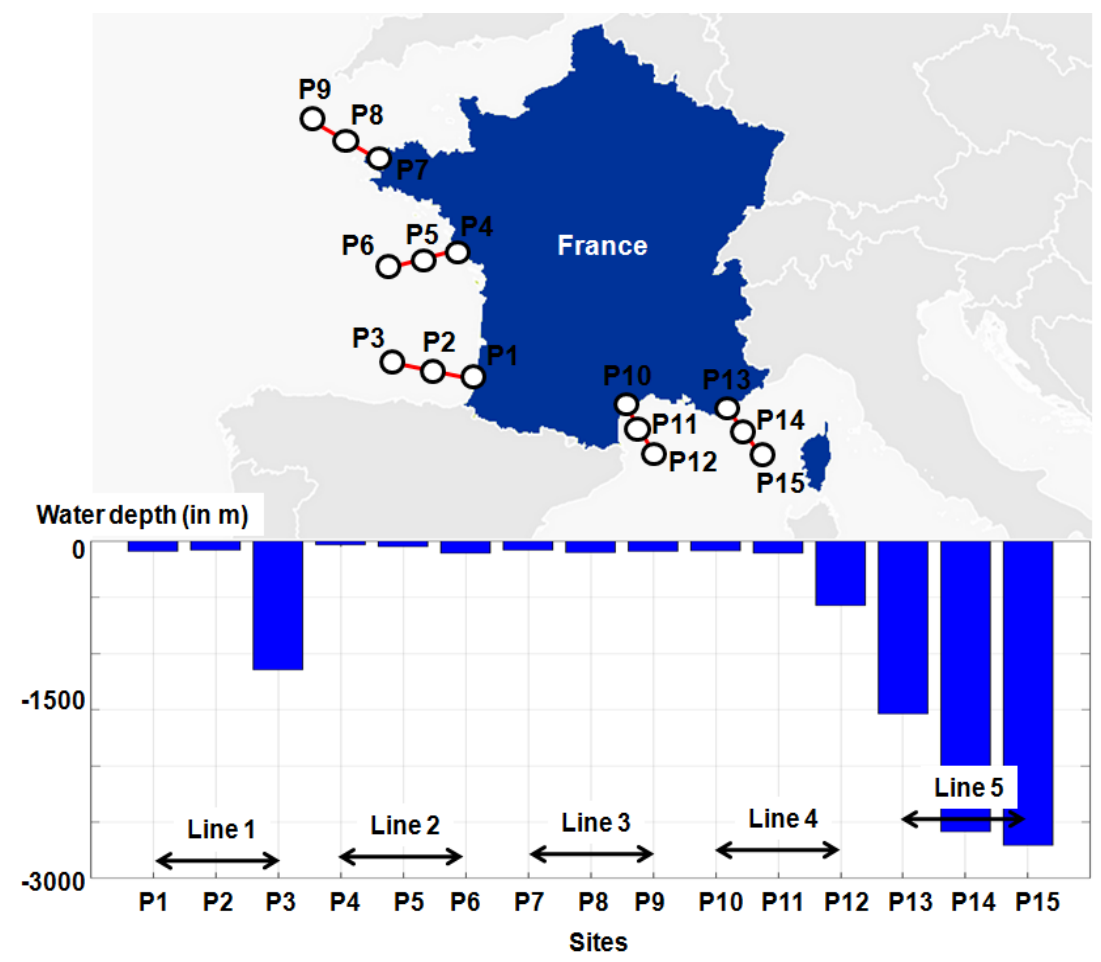

Fig. 1. Map of the target area including the reference sites (and the water depth) considered for evaluation.

The wave parameters considered in this work are the significant wave height $(H s)$ and the mean wave period $(T e)$, and they come from the ERA-Interim dataset, which is a project maintained by the European Centre for Medium-range Weather Forecast (ECMWF). In order to identify the local variations, it was considered for processing a dataset that covers the 10-year time interval (2008-2017), being defined by 4 data per day (corresponding to 00-06-12-18 UTC) and by a spatial resolution of $0.125^{\circ} \times 0.125^{\circ}$, which is the finest grid available on the ECMWF server. 


\section{Results}

Fig. 2 presents the distribution of the average wave power and the evolution of the fluctuation of Wave Energy Development Index (WEDI), considering the total and winter time season (from October to March). The wave power (Pwave), is computed by using the expression corresponding to the deep water conditions, while the WEDI index represents the ratio between the average wave power and the maximum storm wave power (Jwave). A higher WEDI value is usually associated with a potential loss of utilization, and therefore the sites with such characteristics should be avoided [10] [11].

(a) Pwave (kW/m)

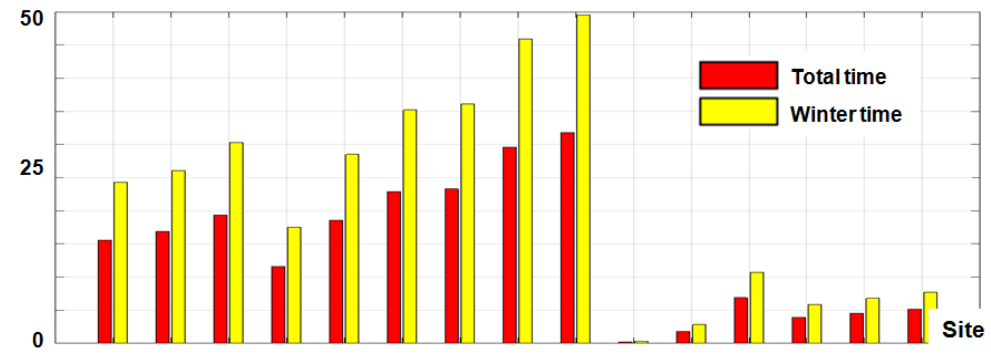

(b) WEDI

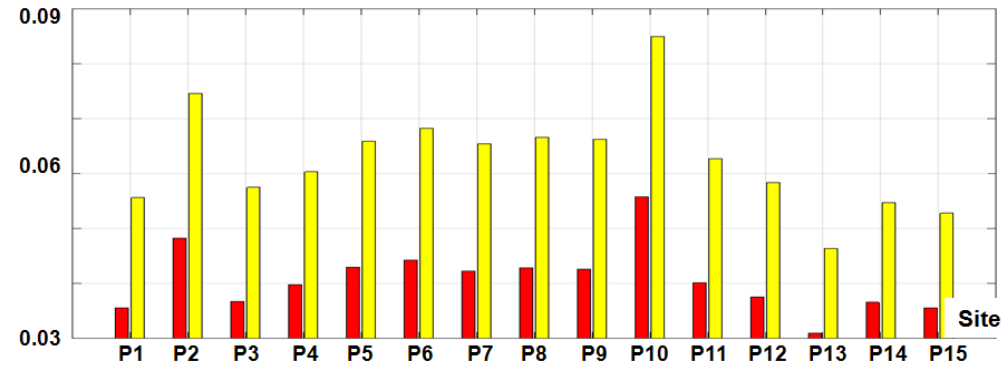

Fig. 2. Wave conditions reported for the 10-year of ECMWF wave data (2008-2017). The results are computed for the total time and winter season, where: (a) Pwave index; (b) WEDI index.

By looking at these results, we can notice that more important values seem to occur in the vicinity of the line 3 (P7, P8 and P9) where a maximum of $49.5 \mathrm{~kW} / \mathrm{m}$ may occur during winter. On an opposite side, we found the group points located in the Mediterranean Sea, where a maximum of $10.7 \mathrm{~kW} / \mathrm{m}$ is accounted by P12. The site P10 seems to be the less attractive for a wave project, this aspect being indicated by the combination from a lower wave power $(0.3 \mathrm{~kW} / \mathrm{m})$ and a higher WEDI index.

For the present work, four WEC systems were considered for assessment, namely: Wave Dragon $(5900 \mathrm{~kW})$; WaveBob $(1000 \mathrm{~kW})$; Oceantec $(500 \mathrm{~kW})$ and Seabased $(15 \mathrm{~kW})$. In the brackets there are indicated the rated powers $(R p)$ for each generator, and more details about these WECs can be found in [4]. The selected systems cover a broader range of powers (from $15 \mathrm{~kW}$ to $5900 \mathrm{~kW}$ ), being possible to estimate in this way the variations of a similar WEC on the market. In order to obtain the expected power $(E p)$ output for each WEC, the bivariate distribution $(H s \times T e)$ specific to each site was combined with the power matrix of each WEC. Another important index is the capacity factor (in \%), which is defined as the ratio between the $E p$ and $R p$ index, where a $100 \%$ will be associated to an ideal situation [12], [13].

In Fig. 3 it is presented the distribution of the WEC performances, which were indicated for the total and winter time. As expected, the sites from the Atlantic Ocean indicate the best performances, which are better highlighted by the Wave Dragon in terms of the expected electric power. For the sites P1-P9 the Wave Dragon presents values in the range $969 \mathrm{~kW}-2048 \mathrm{~kW}$ (winter time), while a maximum of 2849 $\mathrm{kW}$ may be reached in winter by this WEC in the vicinity of the site P9. Regarding the rest of the WECs, we can mention that during the winter season a maximum of $244 \mathrm{~kW}$ is reported by WaveBob, $221 \mathrm{~kW}$ 
for Oceantec and $3.9 \mathrm{~kW}$ for the Seabased. The site P10 indicates values located close to zero, regardless of the WEC and the time interval considered for assessment.

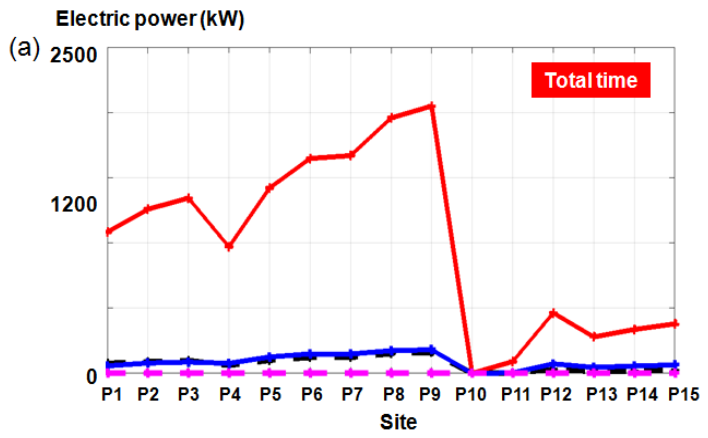

(c)

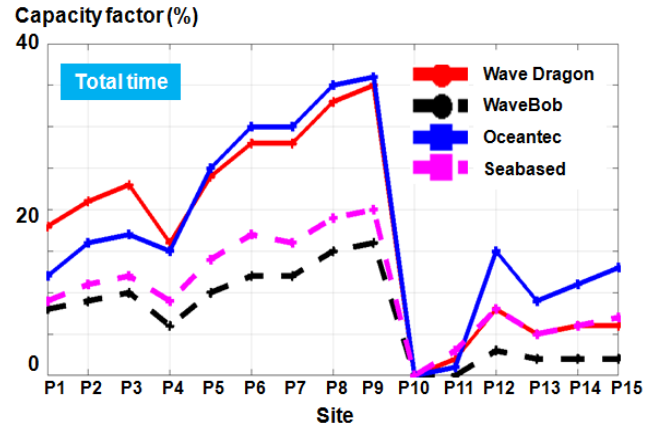

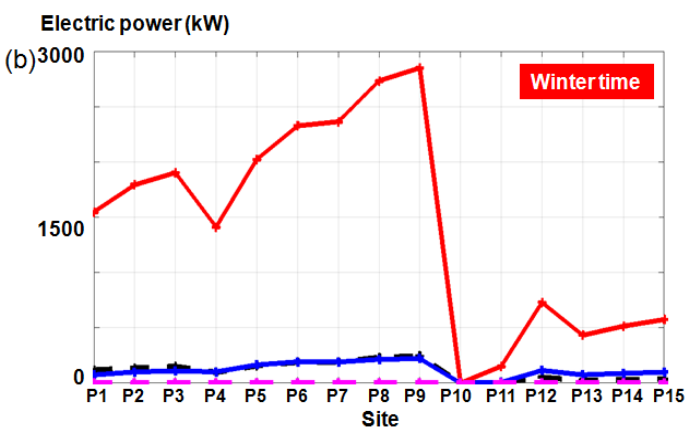

Capacity factor $(\%)$

(d) 50

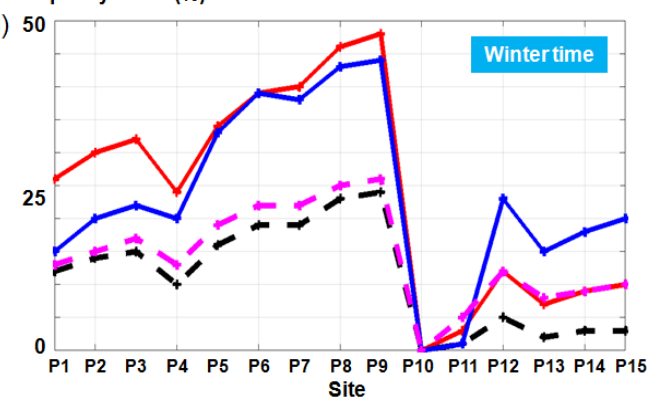

Fig. 3. Performances of the WECs based on the 10-year ECMWF data (2008-2017), where: (a) and (b) Electric power (in $\mathrm{kW}$ ) reported for the total and winter time; (c) and (d) Capacity factor reported for the total and winter time.

As for the capacity factor, we can notice that the efficiency of the Wave Dragon is similar to the one reported for Oceantec, although there is a difference of $5400 \mathrm{~kW}$ between their rated capacities. In this case a maximum of $48 \%$ may be registered during winter, while for the sites P10-P15 (Mediterranean Sea) it seems that the Oceantec indicates the best performances. The WaveBob and Seabased follow a similar evolution indicating a maximum of 20\%-25\% for the site P9, while for the group P10-P15 the values are not exceeding a limit of $12 \%$.

Fig. 4 illustrates the differences reported along the considered reference lines, with the mention that line 4 was not taken into account since the site P10 is defined by lower values than the ones reported close to P11 and P12. The differences (in \%) reported for the electric power were computed by considering as reference base the values reported by the nearest sites from the shore, P1, P4, P7 and P13, respectively. In this way, it is possible to assess the variation of the WEC performances as the distance to the shore increases. The variations reported during the total time are much higher than the similar ones from winter, the systems Oceantec and WaveBob reaching values located close to $100 \%$ as we go from site P4 to P6. Also we can notice that the values gradually increase from line 1 to line 2 , while a more constant evolution seems to be reported by the sites P7-P13.

The monthly variation of the electric power is presented in Fig. 5, where it is possible to make a direct comparison between the lines 1, 2, 3 and 5 by using as a reference the Wave Dragon system and by considering only the end points of these lines for evaluation. The variations reported along the line 2 clearly stand out, being expected that during the summer time these variations to be more severe $(80 \%$ $100 \%$ ). In the case of line 5, a peak of $64 \%$ is reported for June, compared to the lines 1 and 3 were the values are not exceeding $35 \%$. 
(a)

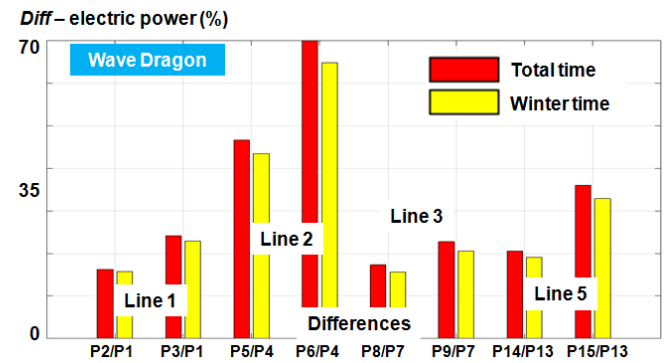

(c) Diff-electric power (\%)

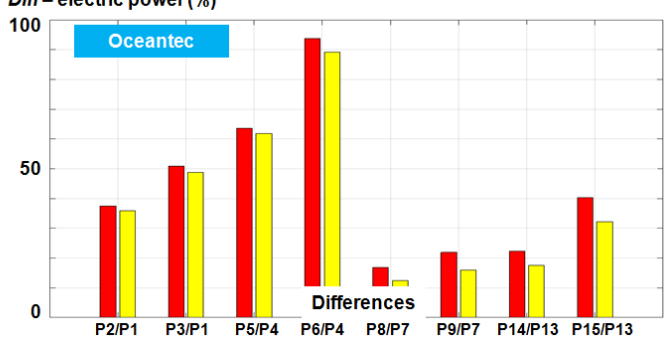

(b) Diff-electric power $(\%)$

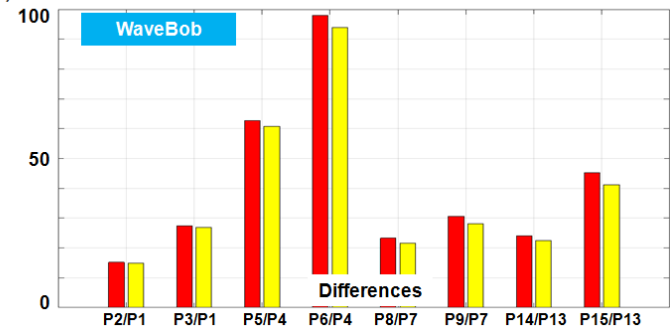

(d) Diff-electric power (\%)

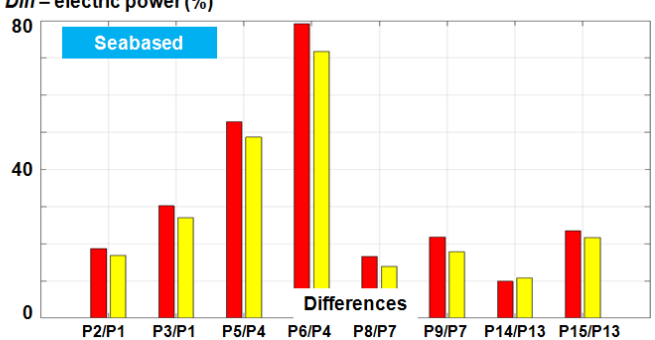

Fig. 4. Electric power variations reported for the reference sites located along the lines 1, 2, 3 and 5. Values reported for the wave converters: (a) Wave Dragon; (b) WaveBob; (c) Oceantec; (d) Seabased.

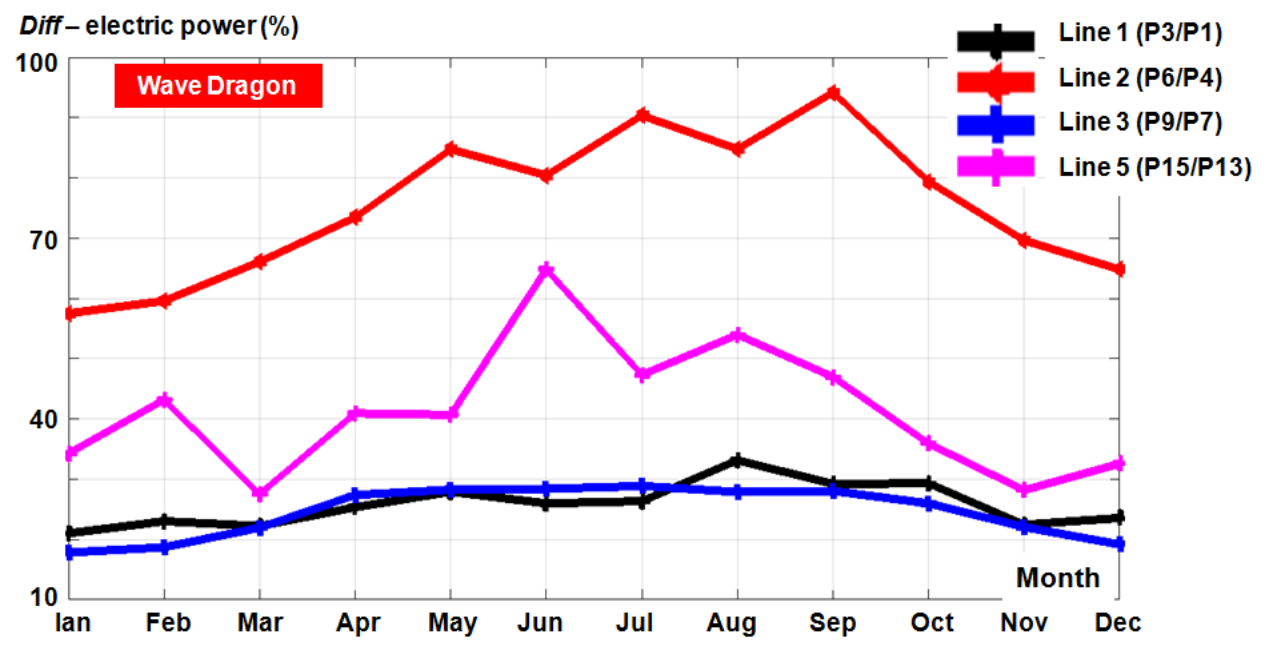

Fig. 5. Monthly variations of the electric power reported for the Wave Dragon.

\section{Conclusions}

In the present work, the general performances of several wave energy converters, which may operate in the French coastal waters, were discussed considering sites from the North Atlantic Oceans and from the Mediterranean Sea, respectively. In order to assess the local variations, a fine resolution wave database $\left(0.125^{\circ} \times 0.125^{\circ}\right)$ coming from the ERA-Interim project was processed, being noticed that in the case of the site P10 the wave energy seems to report a much lower level. More important wave resources were reported on the western coasts, especially along the sites P7, P8 and P9. The electric performances of the WEC are directly related to the rated capacity of each system, but in terms of efficiency it seems that a WEC similar to the Oceantec device may be considered an attractive solution. Finally, it must be mentioned that since France has a long history in the wave energy and there is interest for this sector on a European scale, this region looks very promising in the context when the UK (a leader in this field) will leave the European Union. 


\section{Acknowledgments}

This work was carried out in the framework of the research project REMARC (Renewable Energy extraction in MARine environment and its Coastal impact), supported by the Romanian Executive Agency for Higher Education, Research, Development and Innovation Funding - UEFISCDI, grant number PN-III-P4-IDPCE-2016-0017. The ERA-Interim data used in this study have been obtained from the ECMWF data server.

\section{References}

[1] Cruz J. Ocean Wave Energy: Current Status and Future Prespectives Springer Science \& Business Media, 2007.

[2] Khan N, Kalair A, Abas N, Haider A. Review of ocean tidal, wave and thermal energy technologies Renew. Sustain. Energy Rev. 2017; 72: 590-604.

[3] Babarit A, Clement AH. Optimal latching control of a wave energy device in regular and irregular waves Appl. Ocean Res 2006; 28(2): 77-91.

[4] Rusu L, Onea F. The performance of some state-of-the-art wave energy converters in locations with the worldwide highest wave power Renew. Sustain. Energy Rev. 2017; 75: 1348-1362.

[5] The World Factbook - Central Intelligence Agency 2018 [Online]. Available: https://www.cia.gov/library/publications/theworld-factbook/geos/fr.html. [Accessed: 18-Feb-2018].

[6] Krakowski V, Assoumou E, Mazauric V, Maizi N. Feasible path toward 40-100\% renewable energy shares for power supply in France by 2050: A prospective analysis Appl. Energy, 2016; 171: 501-522.

[7] Sierra JP, White A, Mosso C, Mestres M. Assessment of the intra-annual and inter-annual variability of the wave energy resource in the Bay of Biscay (France) Energy, 2017; 141: 853-868.

[8] Goncalves M, Martinho P, Guedes SC. Wave energy conditions in the western French coast, Renew. Energy. 2014; 62: 155163.

[9] The European offshore wind industry - key trends and statistics 2016 WindEurope, 26-Jan-2017. [Online]. Available: https://windeurope.org/about-wind/statistics/offshore/european-offshore-wind-industry-key-trends-and-statistics-2016/. [Accessed: 19-Feb-2018].

[10] Lavidas G, Venugopal V, Friedrich D. Wave energy extraction in Scotland through an improved nearshore wave atlas, Int. J. Mar. Energy, 2017; 17: 64-83.

[11] Rusu E, Onea F. Joint Evaluation of the wave and offshore wind energy resources in the developing countries Energies, 2017; 10(11): 1866.

[12] Onea F, Rusu E. The expected efficiency and coastal impact of a hybrid energy farm operating in the Portuguese nearshore, Energy, 2016 ;97: 411-423.

[13] Rusu E, Onea F. Study on the influence of the distance to shore for a wave energy farm operating in the central part of the Portuguese nearshore, Energy Convers. Manag, 2016; 114: 209-223. 